\title{
Micellization of D- $\alpha$-tocopheryl polyethylene Glycol 1000 Succinate (TPGS 1000): Thermodynamics and Related Solute Solvent Interactions
}

\author{
HADIATUL AIN BINTI HASANUDDIN ${ }^{1}$, MEOR MOHD AFFANDI MMR ${ }^{1,2}$, \\ MOHAMED SALAMA ${ }^{1}$ and MINAKETAN TRIPATHY ${ }^{1,3 *}$ \\ 'Laboratory of Fundamental Pharmaceutics, Faculty of Pharmacy, Universiti Teknologi MARA (UiTM), \\ 42300 Bandar Puncak Alam, Selangor, Malaysia. \\ ${ }^{2}$ DDH Core, Universiti Teknologi MARA (UiTM), 40450, Shah Alam, Selangor Darul Ehsan, Malaysia. \\ ${ }^{3}$ Brain and Neuroscience Communities of Research, Universiti Teknologi MARA (UiTM), 40450 Shah \\ Alam, Selangor Darul Ehsan, Malaysia \\ ${ }^{*}$ Corresponding author E-mail: minaketan @ puncakalam.uitm.edu.my \\ http://dx.doi.org/10.13005/ojc/300323
}

(Received: June 01, 2014; Accepted: July 20, 2014)

\begin{abstract}
TPGS-1000 has been shown to have wide array of potentials in the field of pharmaceutical sciences. The present study involves the determination of the critical micelle concentration (CMC) of TPGS-1000 in water so to revalidate the value from literature. The conductometric technique has been used for the determination of the CMC value. The obtained value is well agreed with that of the literature. The temperature dependence of the CMC in case of TPGS-1000 has been observed to be negligible. Further the observed specific conductance values during conductometric measurements have been used to evaluate the corresponding values of molar conductance. The values of activation energy related to the different concentrations of TPGS-1000 have been estimated using the Arrhenius equation. The thermodynamic parameters for the micellization process of TPGS-1000 in water have also been calculated.
\end{abstract}

Key words: Micellization, molar conductance, activation energy, and thermodynamics.

\section{INTRODUCTION}

TPGS-1000 (TPGS, D- $\alpha$-tocopheryl polyethylene glycol 1000 succinate) is one type of novel non-ionic surfactant with an average molecular weight of 1513 has been used in several pharmaceutical applications in both liquid and solid dosage forms for increasing solubility and bioavailability after it's by FDA as a safe pharmaceutics adjuvant and also have been utilized in countless TPGS-based drug delivery system (DDS) ${ }^{1}$.

The lipophilic alkyl tail is derived from tocopherol succinate while its hydrophilic polar head portion is formed from polyethylene glycol making the surfactant structure bulky, hence with greater surface area. Vitamin ETPGS-1000 has hydrophile- 
lipophile balance (HLB) value of about $13.2^{2}$.

It is believed to exhibit amphipathic properties and can form stable micelles in aqueous vehicles above its critical micelle concentration (CMC) at concentration as low as 0.02 wt $\%^{3,4,5}$.

Owing to the versatile physicochemical properties TPGS-1000 has been broadly investigated for its emulsifying, dispersing, plasticizer, gelling, spreading, detergency and solubilizing effects on poorly water-soluble drugs(5) .Though there have been several reports on TPGS-1000, pertaining to its micellar behavior and application aspects, no reports regarding the thermodynamics and solution properties of TPGS-1000 and the subsequent micellization are available. Thermo physical investigations can provide information regarding the involved thermodynamic and the solute-solvent interaction(r). Conductometric analyses of the surfactant solutions have been widely utilized to study the thermodynamics of the systems $(6,7,8,9)$ [references]. Hence we intend to determine the $\mathrm{CMC}$ by conductometric technique so to revalidate the value from literature and to elucidate the involved energetics and thermodynamics with further explanation of the solute solvent interactions.

\section{EXPERIMENTAL}

Analytical Reagent grade TPGS-1000 was obtained from Sigma Aldrich,USA and been kept in a vacuum desiccator over anhydrous $\mathrm{CaCl}_{2}$ until required. The solutions were prepared freshly by mass using a Metler balance with a precision of \pm $0.01 \mathrm{mg}$ in doubly distilled deionized and degassed water, and conversion of molality to molarity have been done by standard expression(10).

A conductivity meter with accuracy of \pm 0.5 $\%$ and a conductivity cell (EUTECH Instruments -CON700) has been used for the measurement of conductivity of each sample. The conductance cell was equipped with a water circulating jacket, and the temperature has been controlled within $\pm 0.02 \mathrm{~K}$ with a water thermostat (WiseCircu). The cell constant was usually $1.01 \mathrm{~cm}^{-1}$ which has been calculated by repeated measurements of $\mathrm{KCl}$ solutions. All data has been corrected with specific conductivity of pure water at the experimental temperatures.
Different concentrations $(0.002$ to $0.1 \mathrm{M})$ of TPGS-1000 were prepared separately in double distilled water using $100 \mathrm{ml}$ conical flask. The solutions were filtered and the specific conductivities were measured at four different temperatures of 298.15, 303.15, 308.15 and 313.15 K. For each sample six data points have been considered to calculate the average.

The values of specific conductance were plotted against the concentration of TPGS-1000 in weight fraction scale and the CMC values have been estimated graphically. The different thermodynamic parameters were further computed from the values of $\mathrm{CMC}$ at different temperature.

\section{RESULTS AND DISCUSSION}

The degree of micellization is greatly affected by the nature of the solvent and the temperature as the hydrophobic and hydrophilic interactions change with temperature ${ }^{11}$. In this report, the CMC for the TPGS-1000 in water system were verified at different temperatures and concentrations of TPGS-1000. A clear understanding of the thermodynamic behavior of this amphiphiles can be further explained by the experimental data of the conductance measurements that have been recorded.

The temperature dependency of TPGS1000 micellization is observed to be non-significant as in case of all the studied temperatures. From the conductivity data, the same concentration of $0.02 \mathrm{wt} \%$ is observed to be the CMC as the evident in the (Figure-1). However the conducting values increased with increase in temperature which is attributed to the thermal energy that enhanced the mobility of the solute in solvent hence increasing the values of conductivity. The CMC is determined from the flick point of the plot between conductivities and the surfactant concentration representing the $y$-axis and $\mathrm{x}$-axis respectively ${ }^{12}$.

The thermodynamic parameters during micellization, namely, Gibbs free energy $\left(\Delta^{\circ} \mathrm{G}_{\mathrm{m}}\right)$, enthalpy $\left(\Delta \mathrm{H}^{\circ}{ }_{\mathrm{m}}\right)$ and entropy $\left(\Delta S^{\circ}{ }_{m}\right)$ can be derived from the temperature dependence of the CMC. The free energy change of the micellization process $\left(\Delta^{\circ} \mathrm{G}_{\mathrm{m}}\right)$, is calculated using the equation in the form of (13): 
Table 1: Thermodynamics parameters for TPGS-1000 in water at different temperatures

\begin{tabular}{lccc}
\hline Temperature & \multicolumn{3}{c}{ Parameters } \\
\cline { 2 - 4 } & $-\Delta \mathbf{G p}_{\mathbf{m}}\left(\mathbf{k J ~ \mathbf { ~ m o l } ^ { - 1 } )}\right.$ & $\left.\Delta \mathbf{H p}_{\mathrm{m}} \mathbf{( \mathbf { k J ~ m o l }} \mathbf{~}^{-1}\right)$ & $\Delta \mathbf{S p}_{\mathbf{m}} \mathbf{( \mathbf { k J ~ m o l } ^ { - 1 } \mathbf { ~ K } ^ { - 1 } )}$ \\
\hline $298.15 \mathrm{~K}$ & 9695.57 & $2.49 \mathrm{E}-09$ & 32.51910 \\
$303.15 \mathrm{~K}$ & 9859.82 & $2.49 \mathrm{E}-09$ & 32.52456 \\
$308.15 \mathrm{~K}$ & 10022.40 & $2.49 \mathrm{E}-09$ & 32.52455 \\
$313.15 \mathrm{~K}$ & 10185.10 & $2.49 \mathrm{E}-09$ & 32.52457 \\
\hline
\end{tabular}

Table 2: Values of molar conductance (Ë) at different concentrations and temperatures.

\begin{tabular}{|c|c|c|c|c|c|}
\hline \multirow[t]{2}{*}{$\begin{array}{l}\text { Molar } \\
\text { Concentration }\left(10^{-6}\right)\end{array}$} & $\Lambda$ & \multicolumn{2}{|c|}{$\mu \mathrm{S} \mathrm{cm} \mathrm{cmol}^{-1}$} & \multirow[b]{2}{*}{$\mathrm{T} / \mathrm{K}=313.15$} & \multirow[t]{2}{*}{$\begin{array}{c}E_{\mathrm{a}} \\
\left(\mathrm{kJ} \mathrm{mol}^{-1}\right)\end{array}$} \\
\hline & $\mathrm{T} / \mathrm{K}=298.15$ & $\mathrm{~T} / \mathrm{K}=303.15$ & $\mathrm{~T} / \mathrm{K}=308.15$ & & \\
\hline 13.2 & 110.606 & 115.909 & 117.424 & 118.182 & 3306.63 \\
\hline 26.4 & 53.409 & 55.303 & 56.061 & 56.439 & 2794.82 \\
\hline 39.6 & 36.869 & 38.384 & 39.141 & 39.899 & 3991.65 \\
\hline 52.8 & 31.250 & 31.439 & 32.386 & 32.386 & 2126.45 \\
\hline 66.1 & 27.534 & 27.837 & 28.442 & 29.047 & 2818.94 \\
\hline 132 & 11.970 & 12.197 & 12.348 & 12.727 & 3043.07 \\
\hline 264 & 7.803 & 7.879 & 7.992 & 8.030 & 1561.4 \\
\hline 396 & 5.783 & 5.960 & 5.985 & 6.010 & 1873.59 \\
\hline 528 & 6.023 & 6.004 & 6.004 & 6.023 & 247.17 \\
\hline 661 & 5.295 & 5.507 & 5.522 & 5.537 & 2142.34 \\
\hline
\end{tabular}

$$
\Delta^{\circ} \mathrm{G}_{\mathrm{m}}=R T \ln \mathrm{X}_{\mathrm{CMC}}
$$

The enthalpy $\Delta^{\circ} \mathrm{H}_{m}$, is obtained by employing Van't Hoff's equation that is in the form of

$$
\Delta \mathrm{Hp}_{\mathrm{m}}=-\mathrm{RT}^{2}\left(\mathrm{~d} \ln \mathrm{X}_{\mathrm{CMC}} / \mathrm{dT}\right)
$$

Further the enthapy of micellization is estimated from the slope of the plot of $\ln X_{C M C}$ vs $1 / T$. The slope of which shall represent $-\Delta H^{\circ}{ }_{m} / R$ and entropy change, $\Delta^{\circ} S_{m}$ from the well known relationship of Gibbs - Helmholtz equation,

$$
\Delta \mathrm{G}_{\mathrm{m}}^{\circ}=\Delta \mathrm{H}_{\mathrm{m}}^{\circ}-\mathrm{T} \Delta \mathrm{S}_{\mathrm{m}}^{\circ}
$$

The availability of these parameters at a range of temperatures in the water can give valuable insight into the principles which direct the formation of micelles. As can be seen (Table-1), the $\Delta^{\circ} \mathrm{G}_{\mathrm{m}}$ values for TPGS-1000 in the presence of water are negative, which suggest the facts that the process of micellization of TPGS-1000 in water is a favorable and spontaneous process. Further $\Delta^{\circ} \mathrm{G}_{\mathrm{m}}$ values related to the process of micellization are found to increase with increase in the temperature of the system. This further explain the fact that the increment of temperature further assists the process of micellization in terms of spontaneity as the system become more favorable because of the added thermal energy.

The positive $\Delta^{\circ} \mathrm{H}_{m}$ values for the systems containing TPGS-1000 show that the micellization processes are energy consuming or endothermic in nature while the positive $\Delta^{\circ} S_{m}$ values for micellization indicated that the micellar species to be highly disordered in nature and entropy driven within the three-dimensional polymeric structure of water. These results further can be ascribed to the melting of "icebergs" or "flickering clusters" around the surfactant which can contribute to a non-random enhance in packing of hydrocarbon chains within the micellar core ${ }^{14}$. 
Since the mobility of an ion or a non ionic solute whether in solvated or non-solvated state is the important phenomenon for conductance measurement ${ }^{15}$, it is quite reasonable to treat the conductance data similar to the one that used for the rate process taking place with the variation of temperature, i.e,

OR

$$
\Lambda=\mathrm{Ae}^{-\mathrm{Ea} / \mathrm{RT}}
$$

$$
\log \Lambda=\log A-E_{a} / 2.303 R T
$$

Where $A$ is the frequency factor, $R$ is the gas constant and $\mathrm{E}_{\mathrm{a}}$ is the Arrhenius activation energy of the transport process in different concentration of TPGS-1000.From the plot of log $\Delta$ against $1 / T$ and the $E_{a}$ value have been computed from the slope of $\left(=-E_{a} / 2.303 R\right)$ are then recorded in (Table-2). From the result obtained, the calculated values of $\mathrm{E}_{\mathrm{a}}$ are positive marked the fact that the process of micellization TPGS-1000 in water is favourable.

The values of molar conductance $(\Lambda)$ decrease with increase in concentration of the corresponding solution systems containing TPGS1000 and increase with increase in temperature. These observations can explained by the fact that (i) the increase in TPGS-1000 concentration increases the micro viscosity of the system there by decreasing the mobility of the surfactant species, (ii) further at $\mathrm{CMC}$ the formation of micelles also hinders the mobility because of their enhanced hydrodynamic

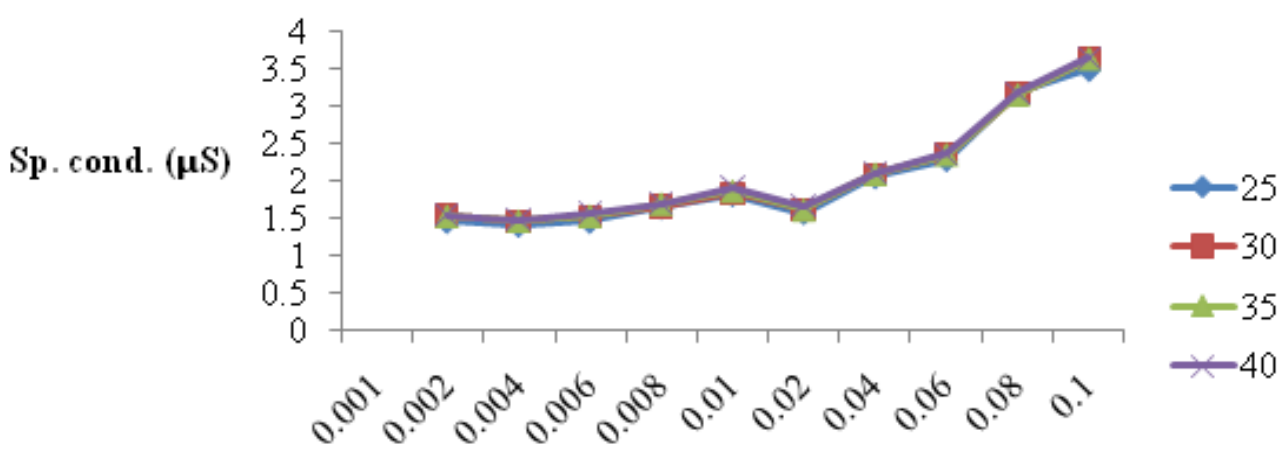

\section{TPGS 1000 concentration $(\% \mathrm{w} / \mathrm{w})$}

Fig. 1: Plots between specific conductivities against the different concentrations of TPGS-1000 at different temperatures in water. [298.15 K, 303.15 K, 308.15 K, 313.15 K]

radii (iii) the increment in temperature causes an increased thermal energy which in turn results in greater bond breaking and variation in vibrational, rotational, and transitional energy of the solution systems containing TPGS-1000 that eventually lead to higher frequency and higher mobility ${ }^{16}$.

\section{CONCLUSION}

In this study, the conductivities of TPGS 1000 in water at different concentrations are determined at four different temperature range between 298.15 and $313.15 \mathrm{~K}$ and it is found that the CMC values of TPGS 1000 are at $0.02 \mathrm{wt} \%$. Besides that, based on the results of thermodynamics parameters, the negative values of the Gibbs free energy of micellization, $\Delta^{\circ} \mathrm{G}_{\mathrm{m}}$ can lead to the conclusion that the formation of the micelles of TPGS-1000 in presence of water is a thermodynamically spontaneous process. The positive $\Delta^{\circ} \mathrm{H}_{m}$ values for the systems containing TPGS-1000 show that the micellization processes are energy consuming or endothermic in nature while the positive $\Delta^{\circ} S_{m}$ values for micellization indicated that the micellar species to be highly disordered in nature and entropy driven within the threedimensional polymeric structure of water. Moreover, the values of molar conductivities $(\Delta)$ decrease with increasing concentration of TPGS 1000 and increase with increase in temperature indicates that there is strong solute-solvent interaction in the system. In a nutshell, the positive values of activation energy, $\mathrm{E}_{\mathrm{a}}$ of the system suggested an activation energy driven orientations of the surfactant leading to micellization in water. 


\section{REFERENCES}

1. Wu, S.H.; Hopkins, W. K. Pharm tech. 1999, 23, 52-69 ..

2. Ke, W.; Lin, S.; Ho, H.; Ming-Thau. J Cont Rel,2005, 102(2), 489-507.

3. Sadoqi, M.; Lau-Cam, C. A.; Wu, S. H. J Colloid Interf Sci,2009 333(2), 585-589.

4. Guo, Y.; Luo, J.; Tan, S.; Otieno, B. O.; Zhang, Z. Euro J Pharm Sci, 2013 49(2), 175-186 (2013).

5. Strickley, R. G. Pharm res, 2004, 21(2), 201230.

6. Mohamed M, Tripathy M, Majeed A.A, Arab J Chem, 2013, http :// dx. doi.. org/ 10.1016 /j . arabjc. 2013. 06. 022.

7. Solanki C. S.; Tripathy S.; Tripathy M K.; Dash U N. E-J Chem, 2010, 7(S1), S223230(2010).

8. Tripathy S and Kar P. K, Orient J Chem, 2013, 29(3), 1103-1109.

9. Tripathy S, Tripathy MK, Kar P K, Majeed A
B A, Chem. Sci. Trans, 2013, 2(1), 208- 212.

10. Robinson R. A and Stokes R. H, Electrolyte Solutions, Butterworth publications, London, 1955, 30.

11. Sulthana, S.B.; Rao, PVC.; Bhat, SGT.; \& Rakshit, A.K. J Physi Chem B,1998, 102(48), 9653-9660 .

12. Ghosh K.K.; Baghel V. Ind J Chem, 2008, 47A, 1230-1233.

13. Tiwari L.K.; Mandal A.; Alam M.S.; Thennarasu $S$ and Mandal A.B. Colloids Surf B: 2011, 82(1)126-133.

14. Mosquera, V.; Ruso, J. M.; Attwood, David, J.; Malcolm N.; Prieto, G.; Sarmiento, F. J Colloid Interf Sci,1999, 210(1), 97-102.

15. Coetzee J F and Ritchi D, Solute solvent interactions; Marcell Dekkar: New York and Basel, 1976.

16. Dash, U.N.; Mahapatra, J.R.; \& Lal, B. J Mol Liq, 2006, 124(1), 13-18. 